\title{
MORPHOMETRIC EVALUATION OF DRY HUMERUS BONE IN A MEDICAL COLLEGE OF EASTERN NEPAL
}

\author{
Chaudhary $R K^{1^{*}}$, Dhakal $A^{1}$, Sah $S K^{1}$, Parajuli $S B^{2}$, Pokhrel $S^{3}$, Deo $S K^{4}$
}

\begin{abstract}
Affiliation
1. Lecturer, Department of Anatomy, Birat Medical College \& Teaching Hospital, Tankisinuwari, Morang

2. Assistant Professor, Department of community medicine, Birat Medical College \& Teaching Hospital, Tankisinuwari, Morang

3. Lecturer, Department of Physiology, Birat Medical College \& Teaching Hospital, Tankisinuwari, Morang

4. Assistant Professor, Department of Physiology, Birat Medical College \& Teaching Hospital, Tankisinuwari, Morang
\end{abstract}

\section{ARTICLE INFO}

\section{Received : 2 August, 2019 \\ Accepted : 25 August, 2019 \\ Published : 31 August, 2019}

(C) Authors retain copyright and grant the journal right of first publication with the work simultaneously licensed under Creative Commons Attribution License CC - BY 4.0 that allows others to share the work with an acknowledgment of the work's authorship and initial publication in this journal.

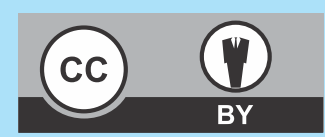

ORA 122

DOI: http://dx.doi.org/10.3126/bjhs.v4i2.25455

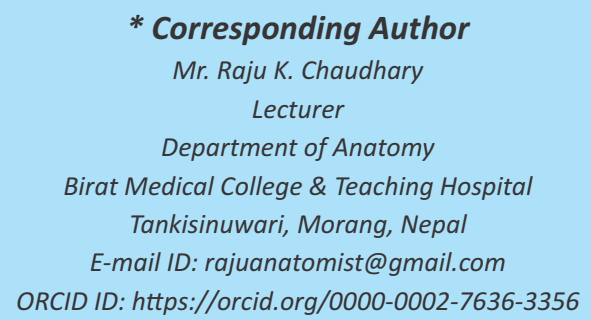

\section{Citation}

Chaudhary RK, Dhakal A, Sah SK, Parajuli SB, Pokhrel S, Deo SK. Morphometric evaluation of dry humerus bone in a Medical College Of Eastern Nepal. BJHS 2019;4(2)9: 729 - 733.

\section{ABSTRACT}

\section{Introduction}

Anthropometric measurement of dry bones are helpful to estimate the stature. It is useful for differentiating unidentified bodies, skeletal remains, surgical procedures and are helpful for anthropologists, anatomists, forensic and surgery.

\section{Objective}

The objective of this study was to find the morphometric measurements of dry Humerus bone available at Birat Medical College and Teaching Hospital of Eastern Nepal.

\section{Methodology}

A cross- sectional study was conducted from 28th June-28th July 2019 in the department of Anatomy of Birat Medical College and Teaching Hospital by taking 59 dry humerus bone. Various parameters such as maximum length, circumference of surgical neck, epicondylar breadth together with position and number of nutrient foramina were measured. Data was collected using osteometric board, vernier caliper and tape. The number, direction and location of nutrient foramina were observed macroscopically by using a fine wire. Ethical clearance was taken from Institutional Review Committee of Birat Medical College and Teaching Hospital.

\section{Results}

Among 59 dry humerus bone, majority (32) were left humerus. No statistical significant difference was found in morphometric measurements between right and left side of dry Humerus bone. The single nutrient foramen was present in $85.18 \%$ and $81.25 \%$ of right and left humeri respectively. Double nutrient foramina in $14.81 \%$ of right humeri and $15.62 \%$ of left humeri. Triple nutrient foramina was only seen in left humeri (3.12\%).

\section{Conclusion}

Single nutrient foramen is most common in both sides of humeri. No statistical significant difference was found between right and left humeri in the different parameters such as maximum humeral length (MHL), vertical diameter of superior articular surface (VDSAS), circumference of surgical neck (CSN), circumferences of middle shaft (CMS), epicondylar breath (EB), medial epicondyle to capitulum (ME - C), transverse diameter inferior articular surface (TDIAS), maximum transverse diameter of trochlea (MTDT), anteroposterior diameter of the trochlea (APDT) and position of nutrient foramina (PNF).

\section{KEYWORDS}

Humerus, morphometry, nutrient foramen 


\section{INTRODUCTION}

Humerus is the longest and strongest bone of the upper extremity. Anatomically, it is located between the two joints: elbow and shoulder. It presents upper and lower ends, and an intervening shaft that exists as part of the shoulder joint and facilitates mobility. Humerus, in addition, forms the elbow joint. It articulates with several skeleton components in several ways, such as it articulates with ulna as hinge, radius as ball \& socket, capitulum as ball and head of the radius as socket. ${ }^{1}$ So, in anatomical point of view, Humerus facilitates different types of movements at upper limb. Surgical neck of humerus is a unique feature that no other long bones posses. In devoid of pelvis and cranium, morphometric analysis is usually done in the remains of the long bones of an individual in anthropology and forensic science studies. ${ }^{2}$ Celbis et, al also stated that in case of absence of lower limb bones the estimation of living stature can be done by remains of upper limb bones such as humerus, radius and ulna. ${ }^{3}$ Anthropometric measurement have been frequently used to estimate the stature from bones and plays vital role in differentiating unidentified bodies, part of bodies or skeletal remains by anthropologists, medical scientists and anatomists for over hundred years. ${ }^{4}$ The knowledge of knowing the mean values of Humerus segments is very important for anatomist and forensic experts and helps the investigator to define the identity of skeleton. ${ }^{5,6}$ Nutrient foramen is an opening in the shaft of Humerus. It steers to oblique nutrient canal passing through cortex and finally open into the medullary cavity. ${ }^{7}$ The nutrient artery enters into medullary cavity through nutrient foramen and the canal which is major source of blood supply to medullary cavity and inner two-third of cortex of the bone and play for an important role in fracture healing. ${ }^{8}$ Additionally, the presence of preserve nutrient blood supply is necessary for the survival of the osteocytes in cases of tumor resection, trauma and congenital pseudoarthrosis. ${ }^{9}$ It is generally single and situated on anterio-medial surface of the humerus near to the midpoint of medial border. ${ }^{10}$ The number and position of foramina varies and may change during the growth of long bones. ${ }^{11}$ The morphometry of humerus, it's number and location of nutrient foramina are variable between different individuals with different races. ${ }^{12}$ Hence this study explore the morphometry of adult humeri of Nepalese subjects which may be useful to anatomists, forensic experts and orthopaedician performing procedures involving bone grafts, fracture repair, joint replacement and vascularised bone microsurgery. Awareness of the number and position of nutrient foramina is beneficial in many surgical procedures. Many studies have been conducted focusing on morphometric measurements of humerus. ${ }^{13}$ They calculated different measurements of humerus and compared the results between both side. However, we could not find any literatures and published articles regarding morphometric measurements of humerus in Nepal. Therefore, the objective of this study is to find the morphometric evaluation of dry humerus bone available at Birat Medical College and Teaching hospital.

\section{METHODOLOGY}

A cross sectional study conducted from 28th June - 28th July 2019 on dry humerus bones of unknown sex ( $n=59: 27$ right and 32 left side) available at laboratory of Department of Anatomy of Birat Medical College and Teaching Hospital. Ethical clearance was taken from Institutional Review Committee of Birat Medical College and Teaching Hospital. The data were analyzed by using Statistical Package for the Social Sciences (SPSS) version 23. Vernier caliper, osteometric board, measuring tape and fine wire were used for identification of nutrient foramen. The operational definition of parameters are given in table 1.

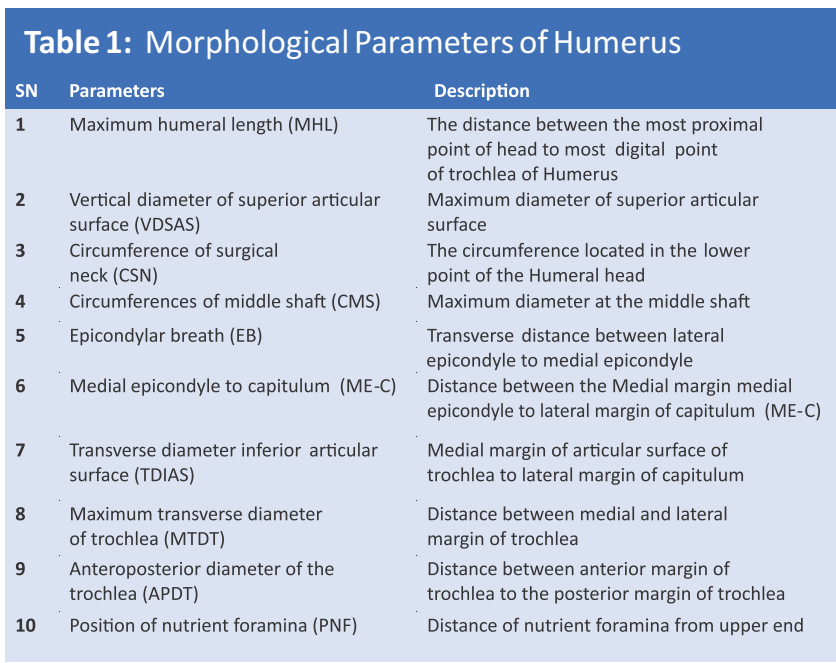

On the surface of bone, a groove was presents adjacent to the nutrient foramen that appeared to continue into it. Location and direction of nutrient foramen in relation with surface and zone were observed and recorded. The position of foramina was divided into three types of zone (Zone I: Foramen present in the upper one third of the bone, Zone II: In the middle one third of the bone, Zone III: In the lower one third of the bone) as shown in figureland other measurement as shown in figure 2 and figure 3.

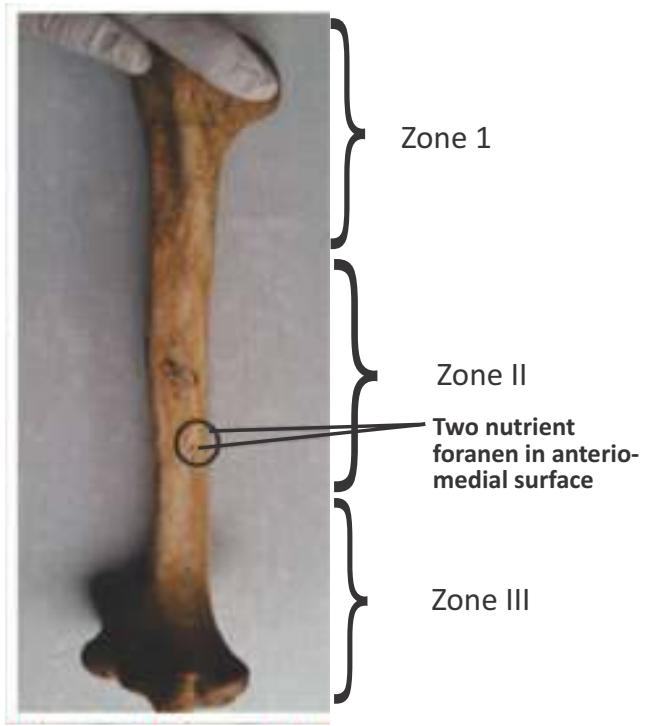

Figure 1: Right humerus showing different zones and location of nutrient foramen 


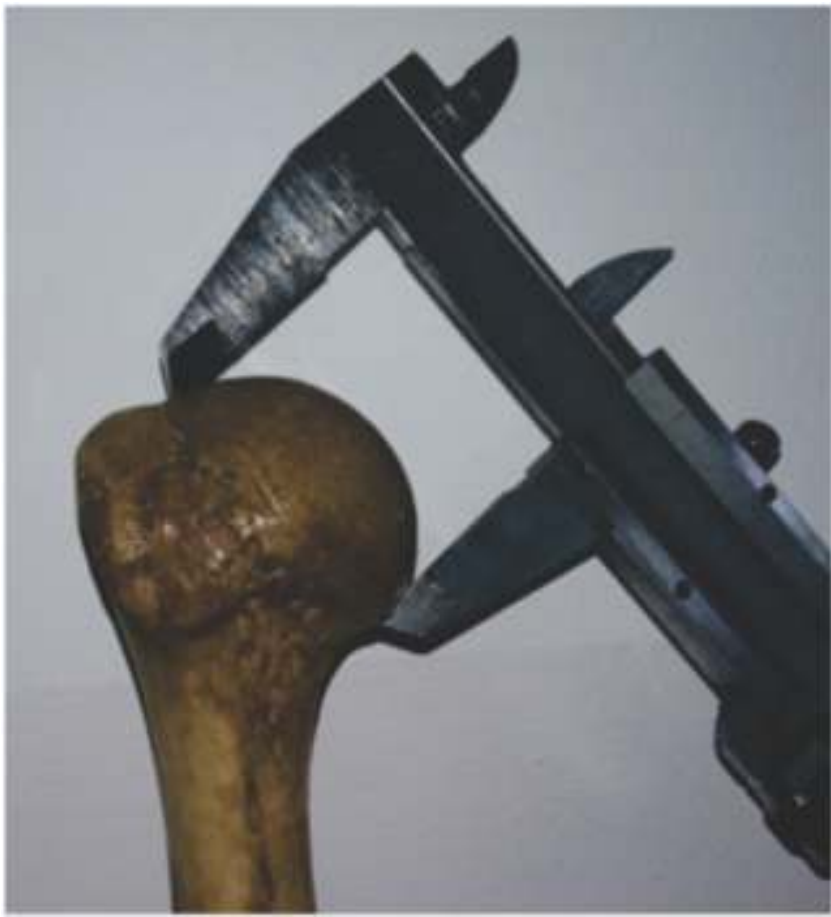

Figure 2: Measurement of vertical diameter of superiorarticular surfaces of humerus

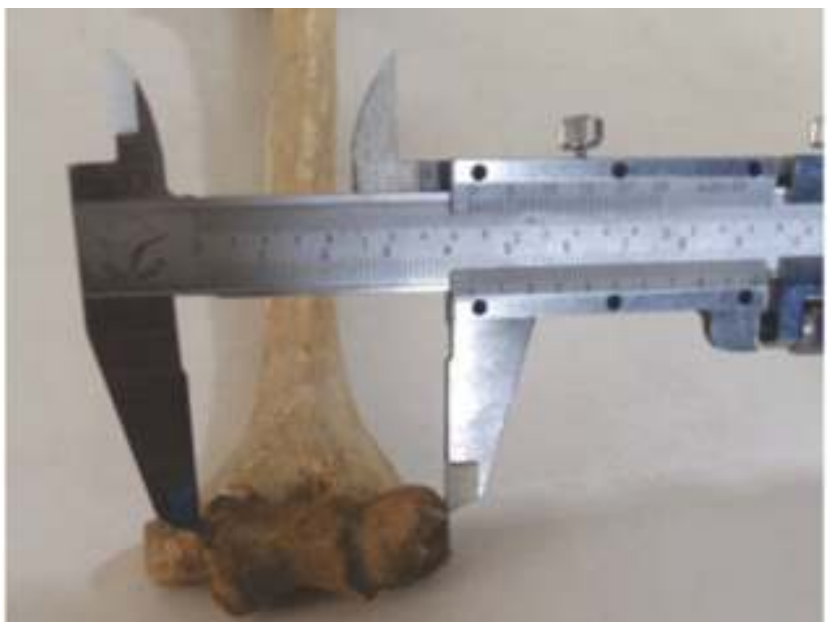

Figure 3: Measurement of the transverse diameter of inferior articular surface of humerus

\section{RESULTS}

Fifty-nine dry humerus bone are used for the study. Among them 27 right and 32 left sided humerus identified. The maximum length of each parameter are shown in figure 4.

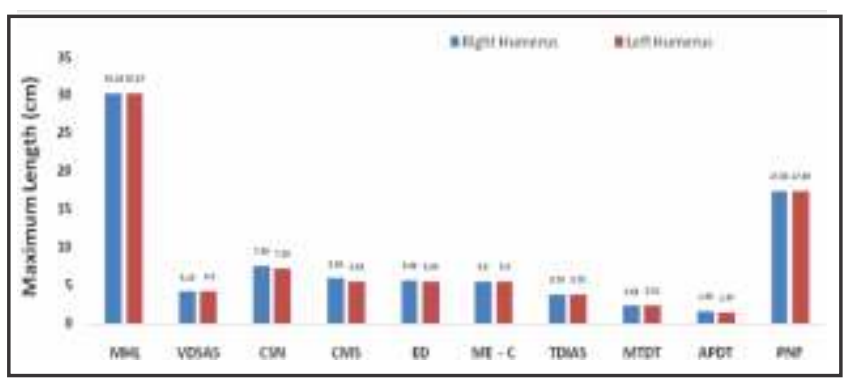

Figure 4: Maximum length of all parameters of right and left humerus
* Maximum humeral length (MHL), Vertical diameter of superior articular surface (VDSAS), Circumference of surgical neck (CSN), Circumferences of middle shaft (CMS), Epicondylar breath (EB), Medial epicondyle to capitulum (ME - C), Transverse diameter inferior articular surface (TDIAS), Maximum transverse diameter of trochlea (MTDT), Anteroposterior diameter of the trochlea (APDT), Position of nutrient foramina (PNF).

The mean and standard deviation are shown in table 2. Right and left humerus was compared for all parameters. As $p$ values of comparative data were $>0.05$, the difference between humeri of both sided with respective concerned parameters were insignificant.

Table 2: Showing mean and standard deviation of different parameters in $\mathrm{cm}$ of right and left humeri

\begin{tabular}{llcc} 
SN & Parameters* & $\begin{array}{c}\text { Right sided } \\
\text { Mean and SD } \\
\text { in centimeter(cm) }\end{array}$ & $\begin{array}{c}\text { Left sided } \\
\text { Mean and SD in } \\
\text { centimeter(cm) }\end{array}$ \\
\hline 1 & MHL & $30.26 \pm 1.63$ & $30.27 \pm 2.01$ \\
2 & VDSAS & $4.19 \pm 0.37$ & $4.30 \pm 0.57$ \\
3 & CSN & $7.59 \pm 0.78$ & $7.24 \pm 0.83$ \\
4 & CMS & $5.89 \pm 0.75$ & $5.53 \pm 0.5$ \\
5 & ED & $5.66 \pm 0.83$ & $5.54 \pm 0.55$ \\
6 & ME-C & $5.50 \pm 0.61$ & $5.50 \pm 0.49$ \\
7 & TDIAS & $3.79 \pm 0.43$ & $3.75 \pm 0.33$ \\
8 & MTDT & $2.33 \pm 0.18$ & $2.41 \pm 0.22$ \\
9 & APDT & $1.58 \pm 0.24$ & $1.47 \pm 0.15$ \\
10 & PNF & $17.38 \pm 2.42$ & $17.39 \pm 1.57$
\end{tabular}

* Maximum humeral length (MHL), Vertical diameter of superior articular surface (VDSAS), Circumference of surgical neck (CSN), Circumferences of middle shaft (CMS), Epicondylar breath (EB), Medial epicondyle to capitulum (ME - C), Transverse diameter inferior articular surface (TDIAS), Maximum transverse diameter of trochlea (MTDT), Anteroposterior diameter of the trochlea (APDT), Position of nutrient foramina (PNF).

The nutrient foramina were present in all humeri.The direction of nutrient foramina was not showing any variation from normal anatomical feature. All the foramina were directed downward or toward the lower end of humeri. The variation in number of foramina and their respective zone is shown in table 3 and table 4 respectively. Nutrient foramina found in right and left humerus are 31 and 39 respectively. The majority of nutrient foramina is located in antero-medial surface of humerus.

Table 3: Position of nutrient foramina at different zones of humerus

$\begin{array}{lcccccc}\begin{array}{l}\text { Position of } \\ \text { nutrient } \\ \text { foramen }\end{array} & \begin{array}{c}\text { Rumber of } \\ \text { Bone }\end{array} & \begin{array}{c}\text { Number of } \\ \text { nutrient } \\ \text { foramen }\end{array} & \begin{array}{c}\text { Number } \\ \text { of Bone }\end{array} & \begin{array}{c}\text { Number of } \\ \text { Nutrient } \\ \text { foramen }\end{array} & \begin{array}{c}\text { Bumber } \\ \text { of bone }\end{array} & \text { Foramen } \\ \text { in Zone \% }\end{array}$


Table 4: Distribution of nutrient foramen in humerus

\begin{tabular}{lccccc} 
Side \& & Numberof & Absent & \multicolumn{2}{c}{ Number of nutrient foramen (\%) } \\
bone & Single & Double & Triple \\
Right $(n=27)$ & 0 & $23(85.18 \%)$ & $4(14.81 \%)$ & 0 \\
Left $(n=32)$ & 0 & $26(81.25 \%)$ & $5(15.62 \%)$ & $1(3.12 \%)$ \\
Total $(n=59)$ & 0 & $49(83.05 \%)$ & $9(15.25 \%)$ & $1(1.69 \%)$
\end{tabular}

\section{DISCUSSION}

Knowledge of the morphometric values of humerus is important in forensic, anatomy and archeology. It is also helpful for the clinician in the treatment of proximal and distal humerus fractures. This study analyzed dry humerus bone available at our Department of Anatomy of Birat Medical College and Teaching Hospital. Many studies have been conducted focusing on morphometric measurements of humerus. ${ }^{13}$ In this present study mean value of the maximum Humerus length ( $\mathrm{MHL}$ ) of right and left side was $30.26 \pm 1.63$ and $30.27 \pm 2.01 \mathrm{~cm}$ respectively without significant statistical difference. Similar findings were reported in studies conducted at Gujarat Indian population, Brazilian population and Turkey population ${ }^{14-16}$ but significant difference was found in the studies conducted at Karnataka Indian population. ${ }^{17}$ In this study, mean value of maximum vertical diameter of superior articular surface (VDSAS) of right and left humerus was $4.19 \pm 0.37$ and $4.30 \pm 0.57 \mathrm{~cm}$ respectively and no significant statistical difference found. Similar findings were reported in studies conducted at Turkey population. ${ }^{16}$ Circumferences of middle shaft (CMS) of our study is lesser than studies conducted at Chinese and Japanese population. ${ }^{18}$ Environmental factors, lifestyle, nutrition, occupation and genetic factor impacts the variation of dimension. ${ }^{19}$ In this study, the mean value of epicondylar breath (EB) of right and left humerus was $5.66 \pm$ 0.83 and $5.54 \pm 0.55 \mathrm{~cm}$ respectively without statistical significance. Similar finding were reported in other studies. ${ }^{14,15,20}$ In this study, the mean value of medial epicondyle to capitulum (ME-C) of right and left humerus was $5.50 \pm 0.61$ and $5.50 \pm 0.49 \mathrm{~cm}$ respectively without statistical significance. Similar finding were reported in other studies. ${ }^{14,15}$ In this study, the mean value of Transverse diameter inferior articular surface (TDIAS) of right and left humerus was $3.79 \pm 0.43$ and $3.75 \pm 0.33 \mathrm{~cm}$ respectively without statistical significance. Similar findings were reported in other study ${ }^{15}$ but in those study statisticaly significant difference found in the left humerus. ${ }^{14}$

In this study, the mean value of maximum transverse diameter of trochlea (MTDT) of right and left humerus was $2.33 \pm 0.18$ and $2.41 \pm 0.22 \mathrm{~cm}$ respectively without statistical significance. Similar findings were reported in other study ${ }^{15}$ but in another study statistical significant difference found in the left humerus. ${ }^{14}$ In this study, the mean value of anteroposterior diameter of the trochlea (APDT) of right and left humerus was $1.58 \pm 0.24$ and $1.47 \pm 0.15 \mathrm{~cm}$ respectively without statistical significance but in those studies statistically significant difference was found in the right humerus $^{14}$ and left humerus. ${ }^{15}$ Acquiring the knowledge of variations of nutrient foramina may help orthopedicians to avoid injury of nutrient artery when performing open reduction thus reducing the chances of delayed or nonunion of the fracture. ${ }^{21}$ In spite of optimal treatment some fractures heal slowly or fail to heal because of severity of the injury, poor blood supply, age and nutritional status of the patient or other factors. ${ }^{22}$ There is maximum chance of injury to nutrient artery during the open reduction of fracture of mid-shaft. ${ }^{23}$ Our present study found single nutrient foramen in $83.5 \%$ of dry humerus. Similar finding (83.3\%) was reported in another study carried out in Nepalese population. ${ }^{11}$ Other studies from different parts of world reported were, north Indian population (80.86\%), ${ }^{24}$ Southern Brazil population (88.5\%), ${ }^{25}$ Uttar Pradesh of India $(90 \%)^{26}$ and Indian population (58\%). ${ }^{27}$ Our present study found double nutrient foramina in $15.25 \%$ of dry Humerus. Similar findings were reported from studies conducted at Nepalese population $(15 \%)^{11}$ and at Indian population $(17.5 \%) .^{28}$ In our study, majority $(88.13 \%)$ of nutrient foramina were found in the middle one-thired (zonell) of the shaft of the humeri. Almost similar findings of nutrient foramina were reported by Rajeev et al (86.66\%), Mansur DI et al (94.84\%) in Nepalese population, Khan As et al (96.2\%) in Pakistani population and Halagatti et al (84\%) in Indian population. ${ }^{11,28,29,30}$

\section{CONCLUSION}

Single nutrient foramen is most common in both sides of humeri. No statistical significant difference was found between right and left humeri in the different parameters such as maximum humeral length (MHL), vertical diameter of superior articular surface (VDSAS), circumference of surgical neck (CSN), circumferences of middle shaft (CMS), epicondylar breath (EB), medial epicondyle to capitulum (ME - C), transverse diameter inferior articular surface (TDIAS), maximum transverse diameter of trochlea (MTDT), anteroposterior diameter of the trochlea (APDT) and position of nutrient foramina (PNF).

\section{LIMITATIONS OF THE STUDY}

We were not able to compare sex, age and race factor with different morphometric parameters.

\section{RECOMMENDATIONS}

More sociodemographic variables and large sample study need to be done to find different morphometric parameter in our setting.

\section{FINANCIAL DISCLOSURE}

The authors would like to declare no financial assistance for this study. 


\section{CONFLICT OF INTEREST}

The authors would like to declare no conflict of interest.

\section{ACKNOWLEDGEMENT}

The authors would like to acknowledge the Institutional Review Committee of Birat Medical College and Teaching Hospital. We are thankful to our laboratory staffs.

\section{REFERENCES}

1. Capo JT, Criner KT, Shamian B, Exposures of the humerus for fracture fixation. Hand clinics. 2014 PMID: 25440069

2. Nath S, Badkur P. Reconstruction of stature from long bone lengths. Int. J. Osteoarchacol.2002;1:109-14

3. Celbis $\mathrm{O}$ Agrithis, H. Estimation of stature and determination of sex from radial, ulnar bone lengths in a Turkis Corpse sample. Forensic Sci. Int. 2006; 158 (2-3): 135-9.

4. ÖzaslanA, İşcan M., Ö zaslan, I., Tuğcu H. and Koç S. Estimation of stature from body parts. Forensic Science International.2003; 132(1), 40-45.

5. De Mendoncea, M.C. Estimation of height from the length of long bone in a Portuguese adult population. Am. J. Phys. Anthropol. 2000; 112(1): 39-48.

6. Mall G, Hubig M, Buttner, Kuznik J, Penning R, et al. A sex determination \& estimation of stature from the long bones of the arm. Forensic Sci Int. 2001;117(1-2): 23-30. DOI: 10.1016/S039-0738(00)00445-X•

7. Krishna G BD Chaurasia's Hand Book of General Anatomy, Blood supply of bone. 2011.

8. Standring S. Gray's Anatomy.(2008)40th ed. Churchill Living stone Elsever 798

9. Sendemir, Cinema A. nutrient foramina in shafts of lower limb long bones: situation \& number. Surg. Radio\& Anat. 1991;13:105-8

10. Bokariya P, Gudadhe D, Kothari R, Murkey PN, Shende MR. Comparison of humerus and femur with respect to location and number of nutrient foramen. Indian J forensic Medi Pathol. 2012; 5(2): 79-81.

11. Rajeev M, Powar BP. A Study of Humerus Bone of Nepalese Origin. Journal of Human Anatomy.2018; 3(2): 1-4. DOI: 10.23880/ jhua16000133

12. Dalia Mohamed Alia, Fatma Alzhraa Fouad Abd Elbaky. Sex identification and reconstruction of length of humerus from its fragments: An Egyptian study. Egyptian Journalof Forensic Sciences. 2016;6(2):48-55. https://doi.org/10.1016/j.ejfs.2016. 03.003

13. Somesh M. S.; Latha V. Prabhu; Shilpa K.; Mangala M. Pai; Ashwin Krishnamurthy \& B. V. Murlimanju. Morphmetric study of the humerus segments in Indian Population. Int. J Morphol.2011; 29 (4):11741180.http://dx.doi.org/10.4067/S0717-9502201100-0400017

14. Ashiyani et al: The Morphometric Measurement of Segments of Humerus. Journal of Research in Medical and Dental Science. 2016;4(1): 38-39. DOI: 10.5455/jrmds.2016418

15. Salles, $A D$, Carvalho, CRF, Silva, DMand Santana, LA. Reconstruction of humeral length from measurements of its proximal and distal fragments. Braz. J. Morphol. Sci. 2009; 26(2): 55-61.
16. Aydin kabakci AD, Buyukmumcu M., Yilmaz M.T, Clcekcibasi A.E, Akin D., Cihan E. An osteometric study on humerus. Int. J. Morphol. 2017; 35(35): 219-226.

17. Desai SD, Shaik HS. A Morphometric study of Humerus segment . J Pharm. Sci \& res. 2012; 4(10):1943-1945

18. Işcan MY, Loth SR, King CA, Shihai D, Yoshino M. Sexual dimorphism in the humerus: a comparative analysis of Chinese, Japanese and Thais. Forensic Sci Int. 1998; 98(!-2): 17-29. PMID:10036756

19. Oluwtosin Olalekan Ogedengbe, Sunday Adelaja Ajayi, Omobola Aderigbe Komolafe, Aung Khaingzaw, Edwin Coleride Stephen Naidu and Onyemaechi Okpara Azu.Sex determination using humeral dimensions in a sample from KwaZulu-Natal: an osteometric study. Anat Cell Biol. 2017; 50(3): 180-186.PMC56391, PMID: 29043096

20. AbdelmonemAwadHegazy.Radiographic morphometric study of the normal distal humerus in adult Egyptians.Int J Adv Res. 2013;1 (9): 155-161

21. Joshi H, Doshi B, Malukar O. A study of the nutrient foramina of the humeral diaphysis.NJIRM.2011; 2(2): 4-17.DOI: 10.18231/23942126.2017.0043.

22. Athanasios karpouzos, Evangelos Diamantis, Praskevi Farmaki, Spyridon Savvanis, Theodore Tropis. Nutritional Aspects of Bone Health and Fracture Healing. J Osteoporos. 2017; 2017; 4218472. DOI: 101155/2017/4218472. PMC5804294, PMID:29464131

23. Laing PG. The arterial supply of the adult humerus. The journal of Bone and Joint surgery 1956;38(5):1105-16. PMID: 13367086.

24. Arvind Kumar Pankaj, et al. morphometric study of nutrient foramina of humerus in North Indian Population. Indian Journal of clinical anatomy and Physiology. 2017;4(2):169-172. DOI: 10.18231/2394-2126.2017.0042

25. Pereira GAM, Lopes PTC, Santos AMPV, Silveira FHS. Nutrient foramina in the upper and lower limb long bones: Morphometric study in bones of southern Brazilian adults. Int J Morph. 2011;29(2):514-20

26. Bhatnagar S, Deshwal AK, Tripathi A. Nutrient foramina in the upper and lower limb long bones: A morphometric study in bones of western Uttar Pardesh. Int J Sci Res. 2014;3(1):301-3

27. Mysorekar VR.Diaphysial nutrient foramina in human long bones. J Anat. 1967;101(4): 813-822. PMID: 6059826

28. Halagatti MS, Rangasubhe P. A study of nutrient foramina in dry adult humerii of south Indian subjects.NJCA.2011; 1(2): 76-80.

29. Mansur DI, Manandhar P, Haque MK, Mehta DK, Duwal S, Timalsina B.A Study on Variations of Nutrient Foramen of Humerus with its Clinical Implications. Kathmandu Univ Med J 2016;53(1):78-83.

30. Khan AS, Shah Z, Inayat Q. Anatomical variations in diaphyseal nutrient foramina of humerus in cadavers from khyberpakhtunkhwa, pakistan. Khyber Med Univ J.2014;6(1):18-21 